\title{
The application of a new rapid method of ion mobility spectrometry to measure blood propofol concentrations in video assisted thoracic surgery
}

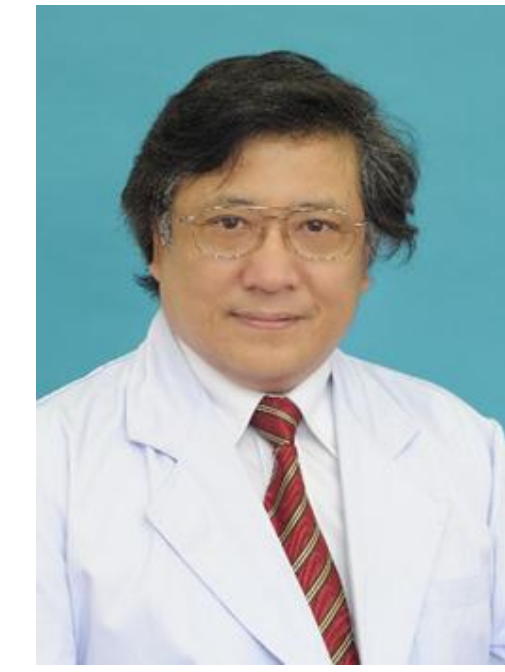

Background and Goal of Study: Monitoring of the intravenous anesthetics is complicated, time consuming and strenuous. Ion mobility spectrometry (IMS) is a widely known apparatus for analysis of gas phase ions, and it has been proved to be an effective method for measuring propofol in blood (measurement within 1 minute without any pre-treatment ${ }^{[1]}$. we aimed to measure blood propofol concentrations by IMS in video assisted thoracic surgery.

Materials and Methods: Fourteen patients scheduled for video assisted thoracic surgery (VATS) under total intravenous anesthesia were enrolled in our study. Propofol and remifentanil were infused to achieve target effect compartment concentrations of $6 \mathrm{\mu g} \mathrm{ml}^{-1}$ (Schnider model) and $5 \mathrm{ng} \mathrm{ml}^{-1}$ (Minto model) respectively. General anesthesia was maintained with propofol and remifentanil at $3.5 \mathrm{ug} \mathrm{ml}^{-1}$ and $3.5 \mathrm{ng} \mathrm{ml}^{-1}$ respectively. $0.5 \mathrm{ml}$ of artery blood was collected from nondominant arm with the patient positioned in 1,3,5 minutes after infusion started; 15,30,60 minutes after commencing onelung ventilation; 5,10,15 minutes after discontinuation of the infusion of propofol. Plasma propofol concentrations were analysed by IMS and compared with concentrations predicted by the TCl system (Diprifusor).

Results and Discussion: The measured concentrations tended to be higher than predicted concentrations. The predicted concentrations were calculated by pharmacokinetics, while the measured concentrations were the true concentrations. BIS were negative correlated with measured concentrations.
Conclusion: IMS provides a rapid and simple method for pointof-care monitoring blood propofol concentrations in VATS.

Reference: 1. Wang X, Zhou Q, Jiang D, Gong Y, Li E, Li H. Ion mobility spectrometry as a simple and rapid method to measure the plasma propofol concentrations for intravenous anaesthesia monitoring. Sci Rep. 2016 Nov 21;6:37525

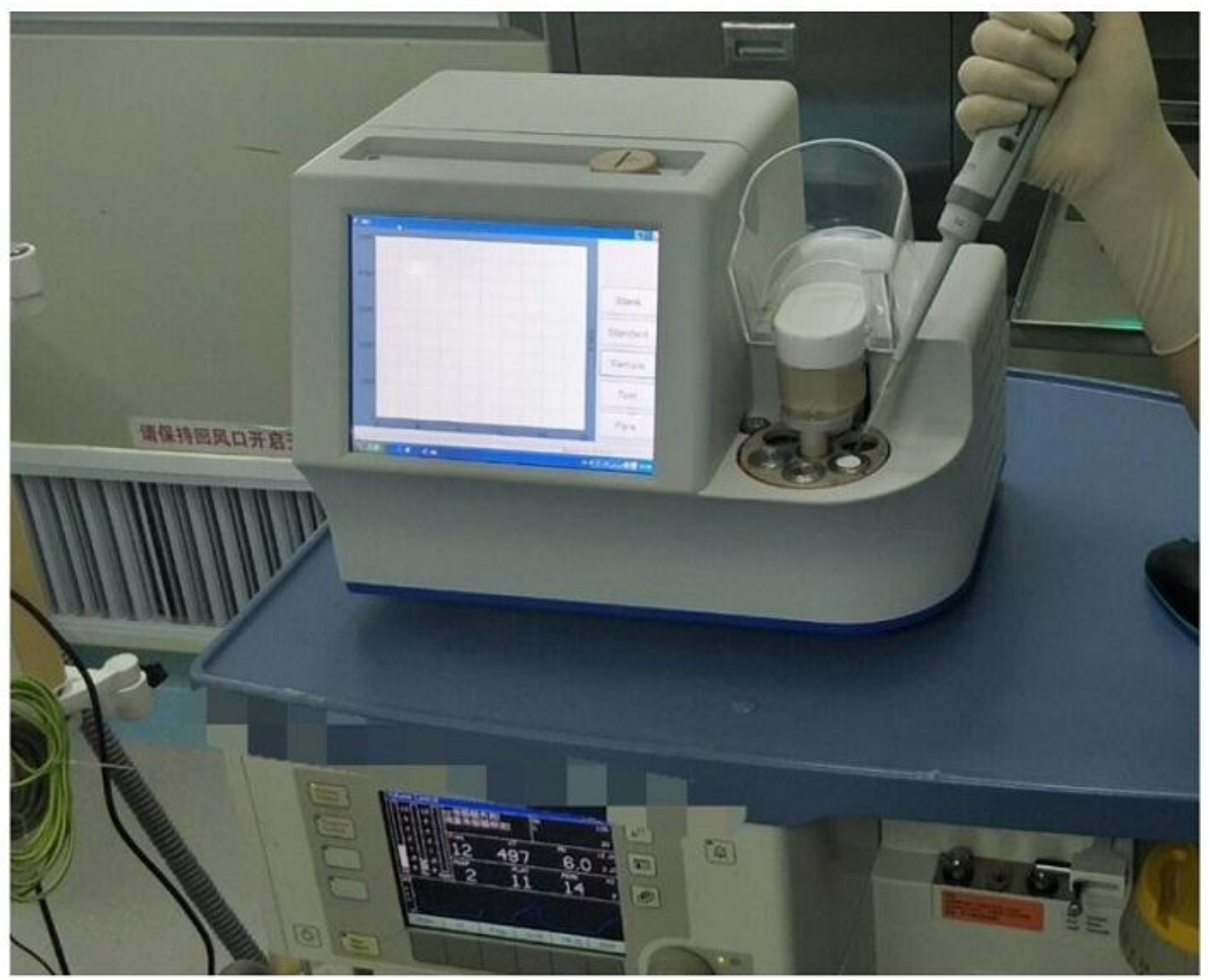

Figure 2 The new ion mobility spectrum applied in this experiment

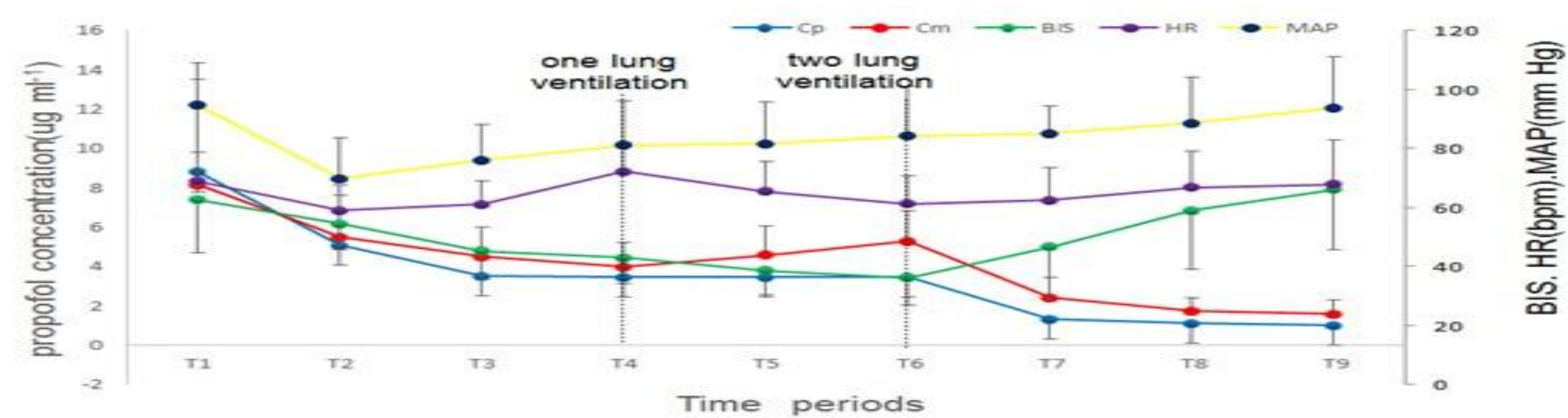

Figure 1. measured concentrations (red circles), predicted concentrations (blue circles), Bispectral Idex (green dircles), heart rate (purple circles) and mean arterial pressure (yellow circles) at different time periods. T1: 1 minute after infusion start; T2: 3 minutes after infusion start; T3: 5 minutes after infusion start; T4: 15 minutes after commencing one-lung ventilation; T5: 30 minutes after commencing one-lung ventilation; T6: 60 minutes after commencing one-lung ventilation; T7: 5 minutes after discontinuation of the infusion; T8: 10 minutes after discontinuation of the infusion; T9: 15 minutes after discontinuation of the infusion. 